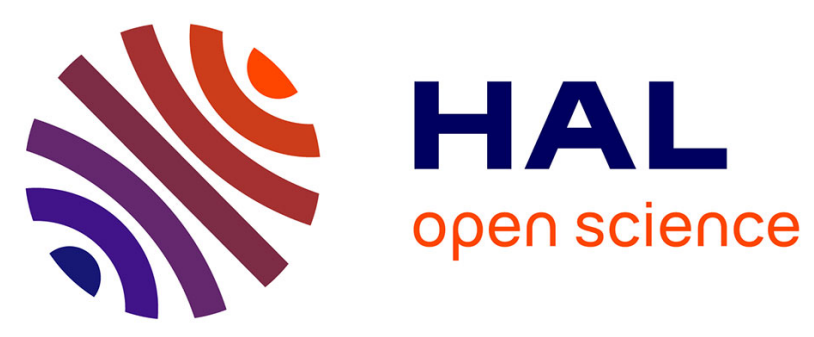

\title{
Sample preparation for an optimized extraction of localized metabolites in lichens: Application to Pseudevernia furfuracea
}

Sarah Komaty, Marine Letertre, Huyen Duong Dang, Harald Jungnickel, Peter Laux, Andreas Luch, Daniel Carrié, Odile Merdrignac-Conanec, Jean-Pierre Bazureau, Fabienne Gauffre, et al.

\section{To cite this version:}

Sarah Komaty, Marine Letertre, Huyen Duong Dang, Harald Jungnickel, Peter Laux, et al.. Sample preparation for an optimized extraction of localized metabolites in lichens: Application to Pseudevernia furfuracea. Talanta, 2016, 150, pp.525-530. 10.1016/j.talanta.2015.12.081 . hal-01254800

HAL Id: hal-01254800

https://hal-univ-rennes1.archives-ouvertes.fr/hal-01254800

Submitted on 10 Feb 2016

HAL is a multi-disciplinary open access archive for the deposit and dissemination of scientific research documents, whether they are published or not. The documents may come from teaching and research institutions in France or abroad, or from public or private research centers.
L'archive ouverte pluridisciplinaire HAL, est destinée au dépôt et à la diffusion de documents scientifiques de niveau recherche, publiés ou non, émanant des établissements d'enseignement et de recherche français ou étrangers, des laboratoires publics ou privés. 


\section{Sample preparation for an optimized extraction of}

\section{localized metabolites in lichens: application to}

\section{Pseudevernia furfuracea}

Sarah Komaty ${ }^{1,3}$, Marine Letertre ${ }^{1,3}$, Huyen Duong Dang ${ }^{1,3}$, Harald Jungnickel ${ }^{4}$, Peter Laux ${ }^{4}$, Andreas Luch ${ }^{4}$, Daniel Carrié $e^{1,3}$, Odile Merdrignac-Conanec ${ }^{1,3}$, Jean-Pierre Bazureau ${ }^{1,3}$, Fabienne Gauffre ${ }^{*, 1,3}$, Sophie Tomasi ${ }^{*, 2,3}$, Ludovic Paquin ${ }^{*}, 1,3$

${ }^{1}$ Université de Rennes 1 - Institut des Sciences Chimiques de Rennes, UMR 6226, ICMV, Campus de Beaulieu, Avenue du Général Leclerc 35042 Rennes France.

${ }^{2}$ Université de Rennes 1 - Institut des Sciences Chimiques de Rennes, UMR 6226, PNSCM, 2 avenue du Pr Léon Bernard 35043 Rennes France

${ }^{3}$ Université Européenne de Bretagne, France

${ }^{4}$ The German Federal Institute for Risk Assessment, Max-Dohrn-Str. 8-10, 10589 Berlin, Germany

ludovic.paquin@univ-rennes1.fr

Abstract Lichens are symbiotic organisms known for producing unique secondary metabolites with attractive cosmetic and pharmacological properties. In this paper, we investigated three standard methods of preparation of Pseudevernia furfuracea (blender grinding, ball milling, 
pestle and mortar). The materials obtained were characterized by electronic microscopy, nitrogen adsorption and compared from the point of view of extraction. Their microscopic structure is related to extraction efficiency. In addition, it is shown using thalline reactions and mass spectrometry mapping (TOF-SIMS) that these metabolites are not evenly distributed throughout the organism. Particularly, atranorin (a secondary metabolite of interest) is mainly present in the cortex of Pseudevernia furfuracea. Finally, using microwave assisted extraction (MAE) we obtained evidence that an appropriate preparation can increase the extraction efficiency of atranorin by a factor of five.

KEYWORDS microwave extraction, lichen, secondary metabolite, grinding process, Tof-SIMS

\section{Introduction}

Lichens are symbiotic organisms composed of a fungus, the mycobiont, and a green alga or one (or several) cyanobacterium the photobiont. While the photobiont provides carbohydrates through photosynthetic processes for the fungus, this latter offers mineral nutrition and moisture to the photobiont[1-3]. About seventeen thousand species of lichens have been described all over the world. While a majority is represented by microlichens which do not exhibit a differentiated thallus, macrolichens can be distinguished by the shape of their thallus (crustose, foliose or fruticose...). The morphology of the thallus is optimized to ensure tight contacts between the photobiont and the mycobiont to favor material exchange for the mutual benefit of each partner. Using carbohydrates provided by the alga or cyanobacterium, lichen fungus produce a great variety of secondary metabolites, many of them being exclusively synthesized in lichens. The biological functions of these metabolites (e.g. depsidones, depsides, diphenyl ether, anthraquinones, xanthones or shikimate derivatives) are generally related to the protection of the 
organism, with anti-oxidant, antimicrobial, photoprotective or antiviral activities and limitation of growth of the neighboring plants. These metabolites, which play a protecting role for the lichens, often form small insoluble crystals on the surface of the hyphae, either in the upper cortex or in the internal medulla[4]. Their localization pattern may be specific of the lichen species and for this reason localization of metabolites has been widely used in taxonomy to differentiate between species.

The secondary metabolites of these organisms, which are tailored to live in the most extreme conditions, are extremely attractive for the pharmacy and cosmetic industries. Therefore the development of optimized processes for the quantitative extraction of lichen metabolites is highly desirable. Prior to extraction, the raw material is generally processed into small pieces or powder. This upstream process ensures easier handling, improved repeatability, and supposedly a larger contact area between the plant and the extracting solvent. However, as mentioned previously, the majority of lichens exhibit a complex sandwich-like structure, with a tight interrelation between the fungus and the alga or bacteria. In addition, the secondary metabolites are not homogeneously distributed in the lichen, but preferentially located in the vicinity of the cortex. Therefore we rationalized that sample preparation should be a crucial step in the extraction process. The main objective of this paper is to address the issue of the preparation of lichen samples for an optimal extraction. We have focused our study on Pseudevernia furfuracea (tree moss) which is largely used as a raw material in the perfume and cosmetic industries (1900 tons/year) [5]. This lichen is particularly interesting due to its richness in aromatic compounds[68]. Three chemical races exist: a race from northern Europe containing olivetoric acid, a race from southern Europe and north Africa containing physodic acid and a race from North America containing lecanoric acid[9]. P. furfuracea are characterized by a gray upper face ruffled of isidia 
and a black lower face with the absence of black spines or fibrils (Figure SI 1a and 1b) [10]. The main compounds (Figure SI 1c) isolated from P. furfuracea are methyl-beta-orcinolcarboxylate, depsides (atranorin and chloratranorin) and depsidones (physodic acid and fumarprotocetraric acid)[11], these metabolites show antimicrobial activities [12] and anti-inflammatory activities for physodic acid [13]. These compounds are mostly hydrophobic, and therefore classical organic solvents (e.g. acetone) are commonly used for their extraction [14] The extracts prepared for perfumery are obtained by the extraction of lichen material with an organic solvent, then treatment with ethanol.

Three standard ways of grinding the raw material (crushing in a blender, ball milling and handgrinding with pestle and mortar) were investigated. These preparations were characterized by SEM and gas adsorption porosimetry, and compared from the point of view of the extraction efficiency. Interestingly, processing with a blender enables to separate the cortex from the medulla, from which two separated extractions were achieved. Finally, using space resolved mass spectroscopy analysis (TOF SIMS), we obtained a fine mapping of the localization of atranorin, which is one of the secondary metabolites of interest.

\section{Material and methods}

\section{Identification of the lichen}

The lichen specimen used in this study was identified as $P$. furfuracea var. furfuracea according to its thalline reactions (Figure SI 2) using potassium hydroxide $\left(\mathrm{K}^{+}\right)$and hypochlorite of sodium $\left(\mathrm{C}^{-}\right)[9]$.

\section{Grinding of the lichen samples}

Blender: for $50 \mathrm{gr}$ of the raw sample, grinding with a mixer was performed with a Brawn multimix MX32 at maximal power (III) for $2 \mathrm{~min}$. 
Milled sample: 50 gr of the raw sample were mixed in a planetary milled Retsch ${ }^{\circledR}$ PM100 using corundum $\left(\mathrm{Al}_{2} \mathrm{SiO}_{3}\right.$ polymorphous) with ten balls $(5$ of $10 \mathrm{~mm}$ diameter, 3 of $20 \mathrm{~mm}$ diameter and 2 of $30 \mathrm{~mm}$ diameter) In this study, we applied grinding for $20 \mathrm{~min}$ at 500 round per second $(\mathrm{rps}) / \mathrm{min}$ with $1 \mathrm{~min}$ in each direction and $5 \mathrm{~s}$ pause between each direction for the first system.

\section{Extraction}

$0.250 \mathrm{~g}$ of milled or mixed $P$. furfuracea $(0.250 \mathrm{~g})$ were put in extraction closed vessel (CEM) with $5 \mathrm{~mL}$ of solvent (water or extraction). The extraction is performed under microwave irradiation, with a maximum of $20 \mathrm{~W}$ irradiation power, at $75^{\circ} \mathrm{C}$ for $15 \mathrm{~min}$. All extraction experiments were repeated three times. After this step of microwave irradiation, the solution was filtered through cotton, concentrated under vacuum, dissolved in acetone for evaluation by Camag ${ }^{\circledR}$ Scanner as described below. The sum of the mass of the compound in the extract was determined by analysis of the total extraction solution after four consecutive extractions with nhexane, diethyl ether, acetone and tetrahydrofuran under microwave irradiations as cited above. Three extractions were done for each solvent. After concentration under reduced pressure of the all organic solvents, a total extract of $P$. furfuracea $(38 \mathrm{mg})$ was obtained.

\section{Quantification of metabolites}

The previously described process [15] was slightly modified. The samples and standard solutions were spotted in the form of bands of width $4 \mathrm{~mm}$, positioned at $15 \mathrm{~mm}$ from the bottom of TLC plates (Merck silica gel $60 \mathrm{~F} 254,20 \mathrm{~cm} \times 10 \mathrm{~cm}$ ), with a Camag® microliter syringe $(4 \mu \mathrm{L}$ deposited). The TLC plates were previously washed with isopropanol. The mobile phase was toluene/ethyl acetate/formic acid (70/25/5) or $n$-hexane/EtOAc/HCOOH (100/30/5). Quantification was carried out under UV light at $252 \mathrm{~nm}$ for atranorin in absorbance/reflectance mode of a Camag® TLC Scanner II or III. Standard solutions for each compound (0.05-0.3 
$\mathrm{mg} / \mathrm{mL}$ in acetone) were used for the preparation of a 5 point calibration curve corresponding to an amount of $0.25-1.5 \mathrm{mg}$. The stock solutions were prepared in acetone, corresponding to 1 $\mathrm{mg} / \mathrm{mL}$ crude extract.

\section{Gas adsorption measurements}

Nitrogen adsorption measurements were carried out using a Micromeritics ASAP 2010 instrument at $77 \mathrm{~K}$. The Brunauer-Emmett-Teller (BET) method was applied to derive the surface area from physisorption isotherm data. The isotherm was constructed point-by-point by the admission and withdrawal of known amounts of gas, with adequate time allowed for equilibration at each relative pressure $\left(\mathrm{P} / \mathrm{P}_{0}\right.$, where $\mathrm{P}$ is the equilibrium vapor pressure and $\mathrm{P}_{0}$ is the saturation vapor pressure). The BET method is based on the determination of the monolayer capacity, i.e. the nitrogen amount corresponding to the adsorption of a complete monolayer $\left(\mathrm{V}_{\text {mono }}\right)$. Prior to adsorption, the samples were out-gassed under vacuum at $50^{\circ} \mathrm{C}$ for $4 \mathrm{~h}$. The surface area $\left(\mathrm{S}_{\mathrm{BET}}\right)$ is determined from a set of ten experimental points of the linear range of the BET plot $\left(0.05<\mathrm{P} / \mathrm{P}_{0}<0.3\right)$ according to:

$$
S_{B E T}=\frac{V_{\text {mono }} \cdot N_{A} \cdot A}{V_{M}}
$$

where $\mathrm{V}_{\text {mono }}$ is the monolayer capacity $\left(\mathrm{cm}^{3} / \mathrm{g}\right)$ at $\mathrm{STP}(273 \mathrm{~K}, \mathrm{P}=101325 \mathrm{~Pa}), \mathrm{N}_{\mathrm{A}}$ is the Avogadro constant, $A$ is the molecular cross-sectional area (for nitrogen, $A=0,162 \mathrm{~nm}^{2}$ at $77 \mathrm{~K}$ ) and $\mathrm{V}_{\mathrm{M}}$ is the molar volume $\left(22414 \mathrm{~cm}^{3} / \mathrm{mol}\right)$ at STP.

TOF-SIMS

ToF-SIMS data acquisition was carried out on an ION-TOF V instrument (ION-TOF GmbH, Munster, Germany) equipped with a $30 \mathrm{kV}$ LMIG Bi cluster ion source. Ion images were acquired using $\mathrm{Bi}^{3+}$ primary ions in the high current bunched mode (i.e., high mass resolution mode). All data were collected by rastering the beams over a $500 \times 500 \mu \mathrm{m}^{2}$ area on the sample 
surface while keeping the fluence below the SIMS static limit of $1 \times 1012$ ions $/ \mathrm{cm}^{2}$. All images contained $512 \times 512$ pixels. A low-energy electron beam was used for charge compensation on the surface samples. The mass resolution $(\mathrm{m} / \Delta \mathrm{m})$ of positive secondary ion spectra was typically between 7000 and 9000 for the $\mathrm{Bi}^{3+}$ primary ions. For the depth sputtering process an argon cluster ion gun (5 keV, argon cluster size 1000) was used for etching the sample surface. The analysis beam was rastered over a $500 \times 500 \mu \mathrm{m}^{2}$ area that was centered inside the sputter crater from the argon cluster ion gun.

\section{Results and Discussion}

Comparison of three types of sample preparation for extraction

Various types of processes including chopping, milling and grinding are commonly used to convert the raw vegetal material into powder or pieces suitable for extraction. Here, the lichen samples were firstly sorted to eliminate tree bark and then cut into approximately $5 \mathrm{~mm}$ pieces with scissors. This sample is hereafter referred to the as the raw sample. Apart from this raw sample, two types of preparations were investigated. In the first case, the raw sample was milled using a planetary ball mill or alternatively a mortar and pestle, which resulted in a homogeneous powder. In the second case, the raw material was ground in a blender, yielding a mixture of small pieces and of a fine powder (FigSI 3a). The weight ratio of powder/pieces was found to be 42/58. The powder (hereafter called cortex powder) obviously results from the abrasion of the cortex of the lichen during grinding in the blender, as the color of the pieces change from light brown in the raw material to white after grinding. This was confirmed by the microscopic observations of cross sections of lichen pieces after grinding in the blender, showing the disappearance of the cortex layer and possibly of the algal layer (Figure SI 3b, to be compared to Figure SI 1b). The remaining pieces mostly consist in the medulla, and are referred to as medulla pieces. 
The extracts are classically obtained from organic solvents using a heat-reflux process, a time and solvent - consuming method. However, since many years, microwave irradiation have been used to extraction of natural products since it is cheaper and environmentally friendly [16-19]. Compared with classical reflux and Soxhlet extractions, microwave - assisted extraction (MAE) generally shows evident advantages such as shorter extraction time, higher extraction yield, higher selectivity and better quality of the target extracts. We have selected acetone as the extraction solvent due to its traditional use in classical natural products extraction $[5,8]$. Following previous studies from our group [15,20], extractions were achieved under microwave irradiation during 15 minutes at $75^{\circ} \mathrm{C}$ using acetone. Then, lichen wastes were removed by centrifugation followed by a filtration. After acetone evaporation, the following metabolites: atranorin, chloroatranorin, methyl beta-orcinolcarboxylate (MOC) (produced from atranorin degradation) and fumarprotocetraric acid, were identified by TLC and NMR analysis. Note that furmarprotocetaric acid, which is present in high amount in other lichen and commonly reacted using thalline reactions was only found at very low amount in P. furfuracea. The amount of extracted atranorin could be quantified using thin layer chromatography (TLC) coupled to a Camag® spectrophotodensitometer operating at $252 \mathrm{~nm}$.

The four samples obtained by ball milling, manual milling and grinding in blender (cortex powder and medulla pieces) were compared from the point of view of the efficiency of extraction, by determining the extraction yield of selected metabolites. The extraction yield is defined as follows:

Yield $\%=($ mass of metabolite in extract $/$ mass of the dried lichen sample $) \times 100$

(The extraction yields of atranorin are gathered Table 1, for different types of preparation of the lichen.) We found that using microwave assisted extraction with acetone, the amount of atranorin 
extracted from the lichen is of the order of a few percent (typically $1-3.5 \%$ depending on the preparation process). The amount of atranorin has been already reported from dried $P$. furfuracea samples with lower value (e.g. $0.11-0.19 \%$ from Slovakia by heat-extraction with acetone)[21]. It is obvious from Table 1 that the process used for grinding the raw material has a strong influence on the amount of extracted atranorin. Thus, the extraction yield of atranorin is $2.77 \%$ after manual milling, whereas it is only $2.25 \%$ when ball milling is applied. For the samples prepared with a blender, the amount of atranorin extracted from the cortex powder (3.5\%) is two orders of magnitude higher than that from the medulla pieces $(0.03 \%)$, suggesting that atranorin is mainly located in the cortex. Taking into account that the cortex powder represents $42 \%$ of the weight of the raw sample (vide supra), the overall extraction yield of atranorin after grinding in a blender is $2.26 \%$, which is comparable to ball milling. We can note that the extraction is more efficient for the cortex powder obtained with a blender compared to all the other samples preparations.

Table 1. Yields of extraction with acetone under microwave irradiation expressed as the weight of atranorin extracted from $100 \mathrm{~g}$ of dry sample, for the different types of preparations.

\begin{tabular}{l|c|c|c|c} 
Preparation & Ball milling & Manual milling (mortar) & Cortex powder (blender) & Pieces (blender) \\
\hline Atranorin \% & $2.25 \pm 0.05$ & $2.77 \pm 0.54$ & $5.16 \pm 0.45$ & $2.43 \pm 0.24$
\end{tabular}

\section{Morphological characterization of the raw sample and after grinding in a blender}

To better understand the effects of the various preparation processes, a full characterization of the sample prior to, and after processing was undertaken. First, the surfaces of the raw sample and of pieces obtained after grinding (medulla pieces) in the blender were both examined using scanning electron microscopy (SEM, Figure 1). It appears clearly that a dense layer of plateletlike crystals is present at the surface of the raw material (Figure 1a). In contrast, most of these 
crystals are removed by the grinding process, leaving exposed worm-like structures, which are identified as hyphae of the medulla.

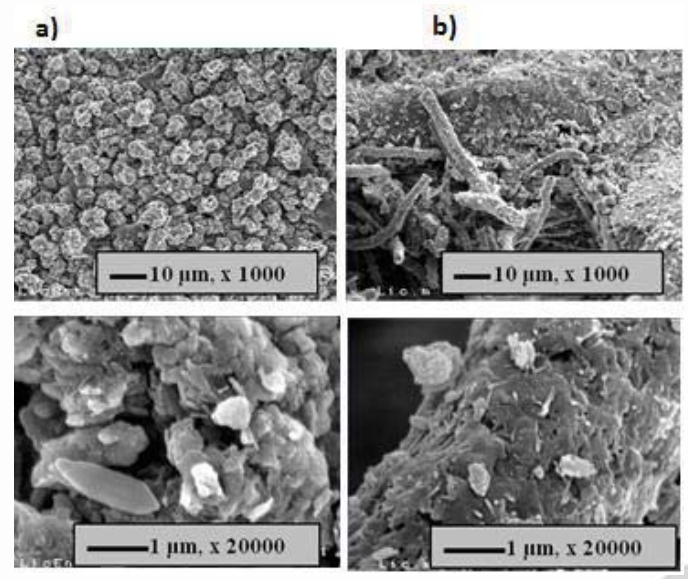

Figure 1. SEM on P. furfuracea after grinding. a) Raw sample b) Pieces obtained after grinding in a blender (medulla pieces)

SEM analysis was also performed on the raw sample, after extraction. Two types of extractions were performed. In the first case, water was used as the extraction solvent (Figure 2a) whereas in the second case, four successive extractions with $n$-hexane, diethyl ether, acetone and then tetrahydrofuran were achieved, in order to model the extraction of all types of metabolites (Figure 2b). Comparison with the raw sample after water extraction (Figure 2a) demonstrates that the numerous crystals formed at the surface of the cortex are dissolved in the mixture of organic solvent. In contrast, extraction with water only partly removes these crystals (Figure $2 b$ ). All together with the extraction yields, these results strongly suggest that the crystal-like platelets exposed at the surface of the lichen correspond to the secondary metabolites. Interestingly, processing the raw sample in a blender grinds the cortex into a metabolite rich powder and leaves the remaining medulla as small pieces, which can be easily separated from the powder. In contrast, milling the sample manually or with a ball mill reduces the medulla and the cortex together into a fine powder from which they cannot be separated. 

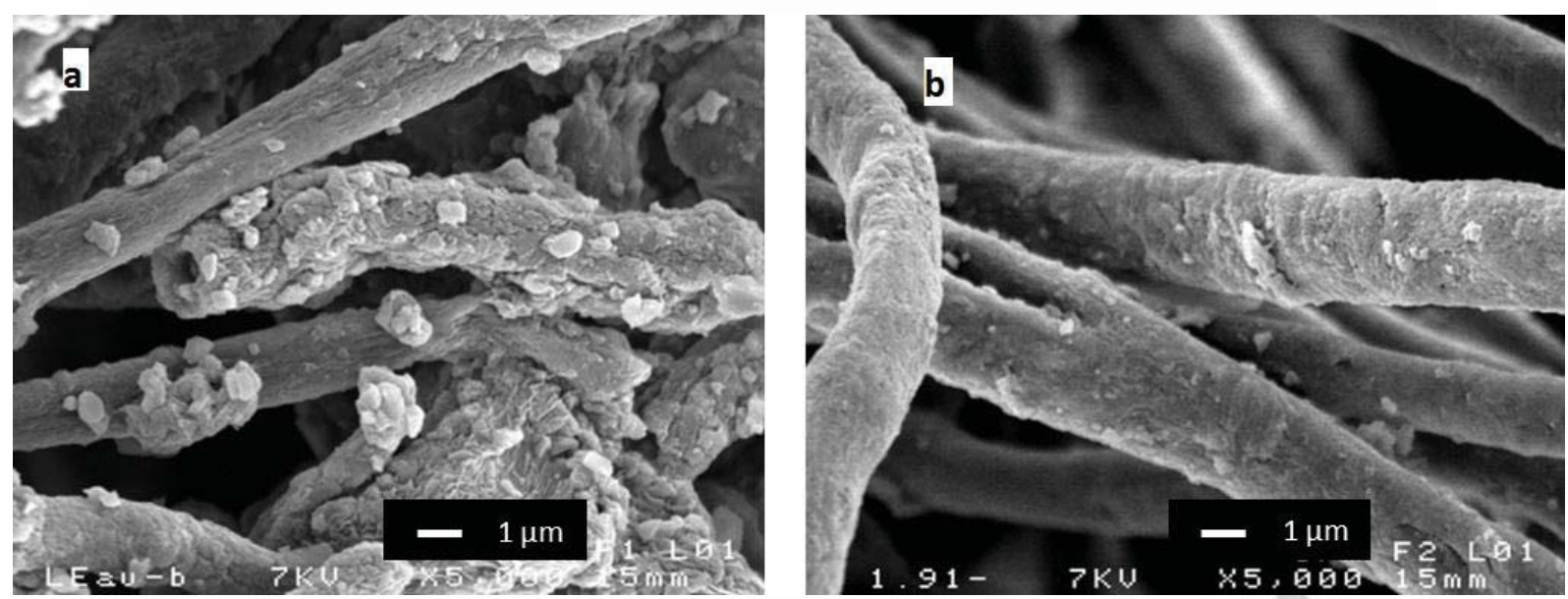

Figure 2. SEM of the surface of the lichen. a) after extraction with water, b) after successive extractions with $n$-hexane, diethyl ether, acetone and then tetrahydrofuran.

Besides homogenization of the sample, grinding into a powder is supposed to increase the contact area between the material and the extraction solvent and therefore improve the extraction yield. We investigated the sample after various types of preparation by gas adsorption which is a powerful technique to evaluate the surface area and porosity of many types of solids or powders such as minerals, soils, industrial or chromatographic adsorbents. Despite its usefulness, this technique was almost never used in the case of vegetal samples, except for the determination of the surface area of plant roots $[22,23]$. Nitrogen adsorption/desorption isotherms were performed on ground and milled samples. In a typical experiment, a known weight of the sample is placed in vacuum at the temperature of liquid nitrogen $(\sim 77 \mathrm{~K})$. Then, successive amounts of nitrogen are introduced. Since adsorbed nitrogen molecules do not participate to the gas pressure, the change of pressure is used to determine the amount of adsorbed nitrogen. The specific surface area of the material is then calculated using the cross sectional area of nitrogen (16.2 $\AA^{2} /$ molecule) in the low pressure regime, assuming the formation of a monolayer, according to the Brunauer-Emmett-Teller (BET) method. 
Table 2. Values of the average pore diameter, total volume of pores and specific surface area for P. furfuracea, after fragmentation (by crushing, milling or hand-grinding) and after a standard procedure of extraction with acetone. Values are presented as means and standard deviations from three measurements.

\begin{tabular}{l|l|l|l} 
& Milled (ball mill) & Milled (mortar) & Medulla pieces (blender) \\
\hline Average pore diameter $(\mathrm{nm})$ & $5.7 \pm 0.5$ & $4.8 \pm 0.4$ & $5.4 \pm 0.4$ \\
\hline Volume of pores $\left(1000 \times \mathrm{cm}^{3} / \mathrm{g}\right)$ & $4.2 \pm 0.2$ & $2.0 \pm 0.1$ & $5.3 \pm 0.2$ \\
\hline Surface area $\left(\mathrm{m}^{2} / \mathrm{g}\right)$ & $3.4 \pm 0.5$ & $1.8 \pm 0.3$ & $6.7 \pm 1.1$
\end{tabular}

All adsorption/desorption isotherm curves show a typical type II adsorption isotherm as shown Figure SI-5. Table 2 lists the values of the surface area determined by the BET model, the average pore diameter (assuming pores with a cylindrical shape) and the total volume of the pores. The data revealed the presence of pores of ca 4-5 $\mathrm{nm}$ diameter for all samples. Therefore, the grinding process does not affect the mean size of the pores. In contrast, the overall volume of the pores is strongly dependent on the type of processing. Particularly, samples milled with a pestle and mortar exhibit a volume of pores twice lower than those milled with the ball mill (2.0 $\pm 0.110^{-3} \mathrm{~cm}^{3} \cdot \mathrm{g}^{-1}$ and $4.2 \pm 0.110^{-3} \mathrm{~cm}^{3} / \mathrm{g}$, respectively). Likewise, the specific surface area is reduced by manual milling $\left(1.8 \pm 0.3 \mathrm{~m}^{2} / \mathrm{g}\right)$ compared to ball milling $\left(3.4 \pm 0.5 \mathrm{~m}^{2} / \mathrm{g}\right)$. Despite its more favorable contact area, it was found that the extraction yield is lower for the samples obtained by ball milling. Indeed, it was observed that for the fine powders, the contact between the solvent and the powder is not optimal due to the presence of air in the powder. Surprisingly, the medulla pieces exhibit larger specific surface area $\left(6.7 \pm 1.1 \mathrm{~m}^{2} / \mathrm{g}\right)$ and volume of pores $(5.3$ $\pm 0.210^{-3} \mathrm{~cm}^{3} / \mathrm{g}$ ) than the powders obtained by milling. This result suggests that the original lichen material is highly porous, and that milling induces a compaction and maybe a rupture of the soft tissues. 
Investigation of localization of atranorin in the lichen

As mentioned above, selective extractions from the cortex or the medulla have shown that the cortex is much richer in atranorin than the medulla. Therefore, we undertook a chemical analysis of these fractions of the lichen to get more information on the localization of atranorin. We first used thalline reactions to this aim. The thalline reactions are colored chemical reactions between a reactant and some lichen metabolites which are used in taxonomy to identify the type of lichen $[24,25]$. These reactions were originally used to reveal the presence of depsides and depsidones which possess a reactive $\beta$-orcinol functional group [14]. Here, we have used the thalline reactions to verify the presence or absence of atranorin in our samples, by simple optical microscopic examination of the coloration. Atranorin reacts with the potassium hydroxide $10 \%$ (K reagent) yielding a yellow color as shown by adding $\mathrm{K}$ onto crystals of pure atranorin (Fig SI4a). When tested on the raw material this thalline reaction is positive (Fig SI4d). When tested on the sample ground in a blender, it is negative on medulla pieces (Fig SI4e) and positive on the cortex powder (Fig SI4f). These observations indicate the presence of atranorin on the upper part of the lichen thallus.

The distribution pattern of atranorin on the surface of the lichen $P$. furfuracea was further investigated using TOF-SIMS which is one of the most sensitive techniques of surface chemical analysis and is based on secondary ionization mass spectrometry (SIMS). The lichen samples were investigated directly without sample preparation [26-28]. In a first series of experiments, we investigated the surface of the raw sample and then the sublayer obtained after argon cluster ion beam etching of the surface (Fig 3). The pictures show the distribution of atranorin (yellow). 

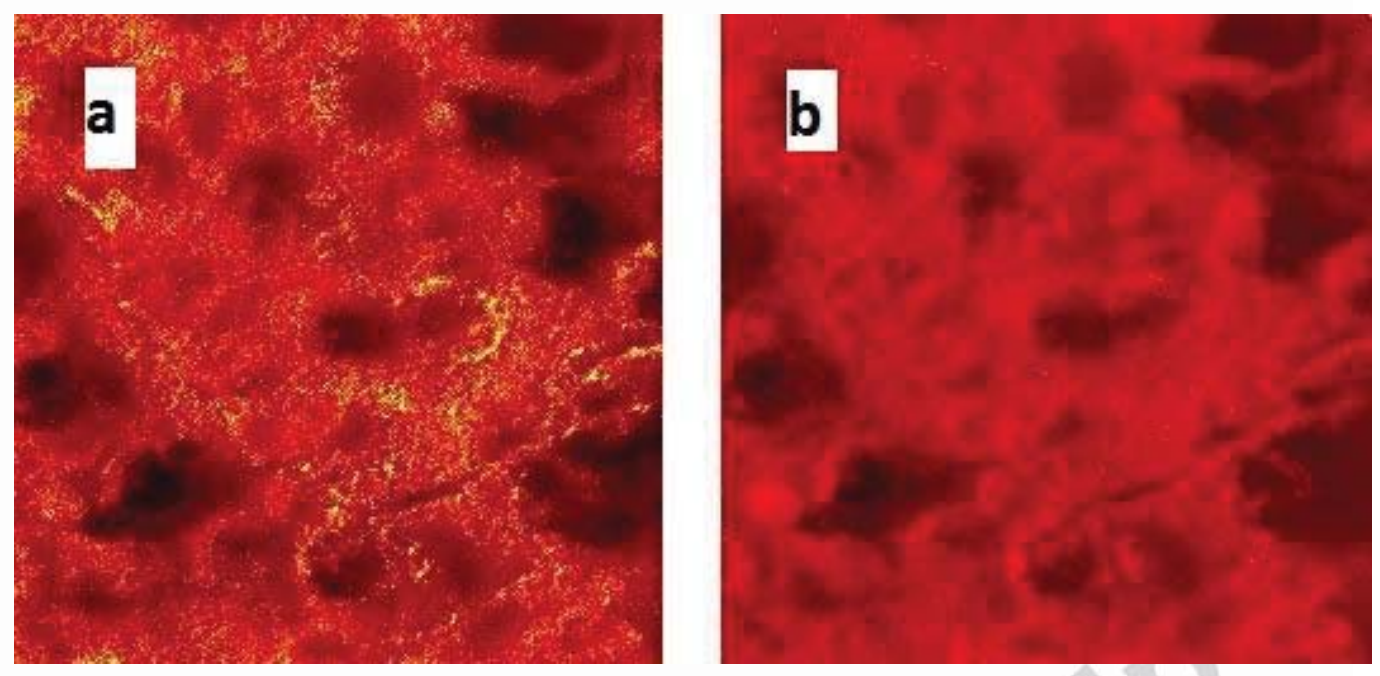

Figure 3. TOF-SIMS images $(500 \mu \mathrm{m} \times 500 \mu \mathrm{m})$ of $P$. furfuracea thallus a) surface $\mathrm{b})$ subsurface (removal of ca $5.5 \mu \mathrm{m}$ surface material) after cluster argon beam cleaning of the surface. The yellow color indicates the atranorin $(\mathrm{M}+\mathrm{H})+$ content and red corresponds to the total ions acquired.

Whereas TOF-SIMS examination of the outer surface (Figure 3a) reveals the presence of significant amounts of atranorin, the ion image of the sub-surface layer shows only very tiny amounts of atranorin (sporadic yellow dots, Figure 3b). Most of the atranorin was removed by etching of the surface and is therefore associated with the outer surface layer of the thallus. In a second series of experiments, the atranorin composition of the lichen was mapped before and after washing the sample with acetone (Fig 4).
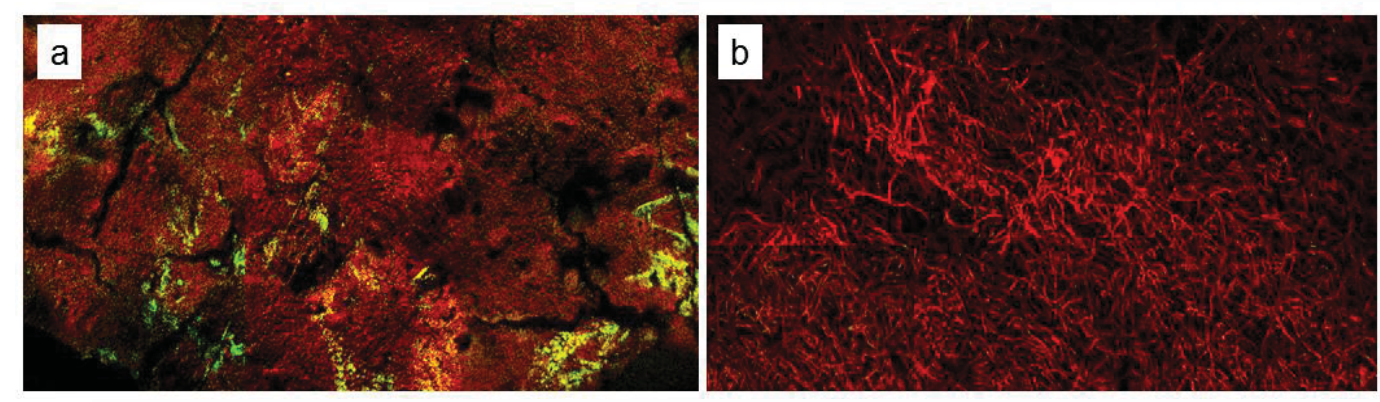
Figure. 4 TOF-SIMS images of atranorin $\left(\left(\mathrm{M}^{+} \mathrm{H}\right)^{+}\right.$; bright yellow areas show high atranorin content, greenish-yellow areas show areas with lower atranorin content) on P. furfuracea washed with acetone in positive ion mode shown as overlay picture with the total ion signal (red). Image area $1.5 \mathrm{~mm} \times 1 \mathrm{~mm}$. a) intact thallus; b) extracted thallus with acetone.

The comparison of Figure $4 \mathrm{a}$ and Figure $4 \mathrm{~b}$ shows the efficiency for the solvent washing step. While in Figure 3 large areas with atranorin content (yellow and greenish-yellow areas) are visible on the surface of the lichen, after the washing step nearly all atranorin was removed. Additionally the solvent washing step resulted in an alteration of the surface into ribbon like formations. These results are consistent with SEM observations, and confirm the presence of an external layer containing atranorin at the surface of the lichen. This layer seems to be removed with the washing step and visible are the ribbon-like structures.

\section{Conclusion}

In this paper we demonstrated that the selection of the grinding process is of major importance for the efficiency of extraction in the case of lichens. Taking Pseudevernia furfuracea and atranorin, one of its main metabolites, as a model system, we determined that the difference in the extraction yield obtained by MAE can reach 2 orders in magnitude, depending on sample preparation. Using analysis techniques inspired from material science, gas adsorption, SEM and TOF-SIMS, we obtained a complete characterization of the surface state and porosity of the lichen during preparations. The surface state of the samples was related to the extraction yields, showing unambiguously that atranorin is prominently present under the form of submicronic particles at the surface of Pseudevernia furfuracea. Milling processes (either ball milling of manual milling with pestle and mortar) reduce the whole lichen into a fine powder, thus rending the metabolites less accessible to extraction. In contrast, grinding with a blender provides a 
mechanical abrasion of the cortex layer containing most of the metabolite, which can be recovered separately as a fine powder. The extraction yields obtained from this cortex powder outweights those obtained from the other samples. This is to our knowledge, the first study of sample preparation, with consideration of the physical state of the samples. It demonstrates that in the case of complex biological material such as lichens, the physical and chemical investigation of the samples is extremely useful to design an optimized process for extraction.

\section{AUTHOR INFORMATION}

\section{Corresponding Author}

Dr Ludovic Paquin

263 avenue du général Leclerc, Campus de Beaulieu, Bat10A porte 213, 35042 Rennes Cedex France.

\section{Author Contributions}

The manuscript was written through contributions of all authors. All authors have given approval to the final version of the manuscript. *These authors contributed equally. (match statement to author names with a symbol)

\section{References}

[1] R. Honegger, Morphogenesis in Lichen Biology, cambridge, 2008.

[2] R. Honegger, Metabolic interactions at the mycobiont-photobiont interface in lichens, Mycota 5 (1997) 209-221.

[3] R. Honegger, Functional Aspects of the Lichen Symbiosis, Plant Biol. 42 (1991) 553-578.

[4] K.-H. Nguyen, M. Chollet-Krugler, N. Gouault, S. Tomasi, UV-protectant metabolites 
from lichens and their symbiotic partners., Nat. Prod. Rep. 30 (2013) 1490-508. doi:10.1039/c3np70064j.

[5] D. Joulain, R. Tabacchi, Lichen extracts as raw materials in perfumery. Part 2: treemoss, Flavour Fragr. J. 24 (2009) 105-116. doi:10.1002/ffj.1923.

[6] W.L. Culberson, C.F. Culberson, A. Johnson, Pseudevernia furfuracea-Olivetorina Relationships: Chemistry and Ecology, Mycologia 69 (1977) 604-614.

[7] R. Tabacchi, J. Gunzinger, Isolement et identification de l'acide furfurique, nouvelle depsidone du lichen Pseudevernia furfuracea (L.) Ach. HCA, Helv. Chim. Acta. 68 (1985) $1936-1939$.

[8] S. Caccamese, R.M. Toscano, F. Bellesia, A. Pinetti, Methyl $\beta$-orcinolcarboxylate and depsides from Parmelia furfuracea, J. Nat. Prod. 48 (1985) 157-158. doi:10.1021/np50037a043.

[9] J. a. Elix, E. Stocker-Wörgötter, Biochemistry and secondary metabolites, Cambridge, 2008.

[10] F. Dobson, Lichens : An illustrated guide to the British and Irish species, 2005.

[11] J. Gunzinger, Etude de la composition chimique de Pseudevernia Furfuracea (L.) Ach. Synthèse d'un depside et d'une depsidone, University of Neuchâtel, 1985.

[12] H. Turk, M. Yilmaz, T. Tay, A.O. Turk, M. Kivanc, NoAntimicrobial activity of extracts of chemical races of the lichen Pseudevernia furfuracea and their physodic acid, chloroatranorin, atranorin, and olivetoric acid constituents, Zeitschrift Fuer Naturforschung, C J. Biosci. 61 (2006) 499-507.

[13] J. Bauer, B. Waltenberger, S.M. Noha, D. Schuster, J.M. Rollinger, J. Boustie, et al., Discovery of Depsides and Depsidones from Lichen as Potent Inhibitors of Microsomal Prostaglandin E2 Synthase-1 Using Pharmacophore Models, ChemMedChem. 7 (2012) 2077-2081.

[14] E. Stocker-Wörgötter, A. Hager, J. a. Elix, Intraspecific chemical variation within the crustose lichen genus Haematomma: anthraquinone production in selected cultured mycobionts as a response to stress and nutrient supply, Phytochem. Rev. 8 (2009) 561569. doi:10.1007/s11101-009-9149-1. 
[15] S. Bonny, E. Hitti, J. Boustie, A. Bernard, S. Tomasi, Optimization of a microwaveassisted extraction of secondary metabolites from crustose lichens with quantitative spectrophotodensitometry analysis, J. Chromatogr. A. 1216 (2009) 7651-6. doi:10.1016/j.chroma.2009.09.009.

[16] M. a. Desai, J. Parikh, Extraction of Essential Oil from Leaves of Lemongrass Using Microwave Radiation: Optimization, Comparative, Kinetic, and Biological Studies, ACS Sustain. Chem. Eng. (2015) 150205121043003. doi:10.1021/sc500562a.

[17] L. Wu, Y. Song, M. Hu, X. Xu, H. Zhang, A. Yu, et al., Integrated microwave processing system for the extraction of organophosphorus pesticides in fresh vegetables, Talanta 134 (2015) 366-372. doi:10.1016/j.talanta.2014.11.035.

[18] K. Thirugnanasambandham, V. Sivakumar, J.P. Maran, Microwave-assisted extraction of polysaccharides from mulberry leaves, Int. J. Biol. Macromol. 72 (2015) 1-5. doi:10.1016/j.ijbiomac.2014.07.031.

[19] C. Li, Z. Lu, C. Zhao, L. Yang, Y. Fu, K. Shi, et al., Ionic-liquid-based ultrasound/microwave-assisted extraction of 2,4-dihydroxy-7-methoxy-1,4-benzoxazin-3one and 6-methoxy-benzoxazolin-2-one from maize (Zea mays L.) seedlings, J. Sep. Sci. 38 (2015) 291-300. doi:10.1002/jssc.201401081.

[20] S. Bonny, L. Paquin, D. Carrié, J. Boustie, S. Tomasi, Ionic liquids based microwaveassisted extraction of lichen compounds with quantitative spectrophotodensitometry analysis, Anal. Chim. Acta. 707 (2011) 69-75. doi:10.1016/j.aca.2011.09.009.

[21] B. Proksa, J. Adamcova, M. Sturdikova, J. Fuska, Metabolites of Pseudevernia furfuracea (L.) Zopf. and their inhibition potential of proteolytic enzymes, Pharmazie 4 (1994) 282283.

[22] G. Jozefaciuk, A. Szatanik-Kloc, Pitfalls and Uncertainties of Using Potentiometric Titration for Estimation of Plant Roots Surface Charge and Acid-Base Properties, Am. J. Plant Sci. 5 (2014) 1862-1876.

[23] G. Jozefaciuk, A. Szatanik-Kloc, Decrease in variable charge and acidity of root surface under Al treatment are correlated with Al tolerance of cereal plants, Plant Soil. 260 (2004) 137-145. doi:10.1023/B:PLSO.0000030175.23904.5a. 
[24] R. Honegger, Ultrastructural studies in lichens lichens, New Phytol. 103 (1986) 797-808.

[25] W. Nylander, Circa novum in studio Lichenum criterium chemicum, Flora. 49 (1866) 198-201.

[26] A. Haase, H.F. Arlinghaus, J. Tentschert, H. Jungnickel, P. Graf, A. Mantion, et al., Application of Laser Postionization Secondary Neutral Mass Spectrometry / Time-ofFlight Secondary Ion Mass Spectrometry in Nanotoxicology : Visualization of Nanosilver in Human Macrophages and Cellular Responses, ACS Nano. (2011) 3059-3068.

[27] F. Draude, S. Galla, A. Pelster, J. Tentschert, H. Jungnickel, A. Haase, et al., ToF-SIMS and Laser-SNMS analysis of macrophages after exposure to silver nanoparticles, Surf. Interface Anal. 45 (2013) 286-289. doi:10.1002/sia.4902.

[28] C.E. Thompson, H. Jungnickel, N.P. Lockyer, G.M. Stephens, J.C. Vickerman, ToF-SIMS studies as a tool to discriminate between spores and vegetative cells of bacteria, Appl. Surf. Sci. 231-232 (2004) 420-423. doi:10.1016/j.apsusc.2004.03.154.

Table of contents

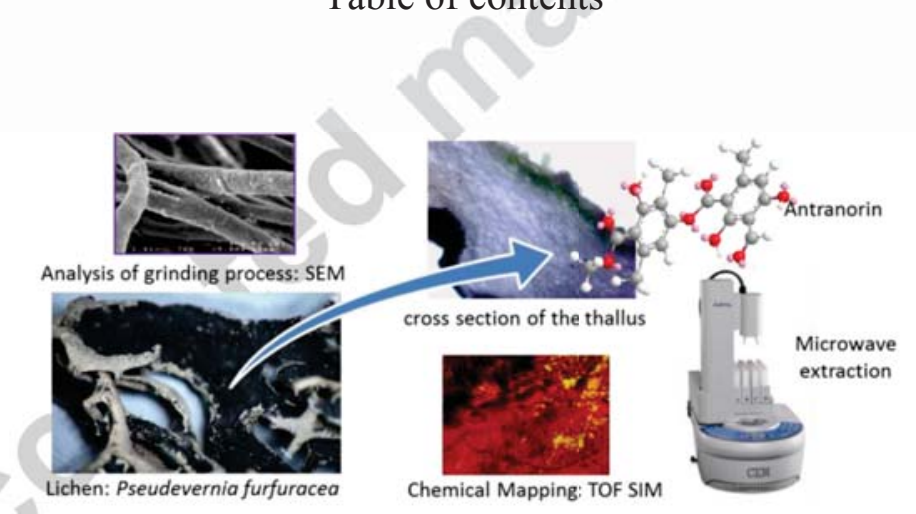

highlight

- Preparation of lichen samples for an optimal extraction

- Investigation of three standard ways of grinding the raw material

- Characterization by SEM and gas adsorption porosimetry

- Fine mapping of the localization of atranorin by TOF SIMS 